\title{
Mullerian adenosarcoma of the cervix: case report with conservative management
}

\author{
Adenosarcoma mulleriano del cérvix: reporte de caso con manejo conservador
}

Javier A. Teco-Cortes ${ }^{1}$, Peter Grube-Pagola ${ }^{*}$, Vicente A. Saldaña-Quiroz ${ }^{2}$ and Georgia Alderete-Vázquez ${ }^{1}$ Department of Anatomic Pathology, Institute of Medical-Biological Research, Universidad Veracruzana; ${ }^{2}$ Obstetrics and Gynecology Department, Hospital Star Médica Veracruz; ${ }^{3}$ Dr. Isabel Ruiz Juárez Private Practice, Veracruz. Ver. Mexico

\begin{abstract}
Background: Mullerian adenosarcoma is a rare gynecological malignancy with a low malignant potential, with biphasic growth, consisting of a benign epithelial element and a malignant mesenchymal element. It occurs in all ages predominating in postmenopausal women. Cervical localization of Mullerian adenosarcomas is rare; however, it is associated with a presentation in young women. The diagnosis is made by anatomopathological study of the lesion and immunohistochemistry. The prognosis is generally good although the recurrence rate is high. Clinical case: We present the case of a 27-year-old patient who attended a gynecological consultation with bleeding and transvaginal flow. During the gynecological examination, a polypoid lesion originating in the cervix was identified, which was removed by torsion and was diagnosed as Mullerian cervical adenosarcoma. Subsequently, a cervical cone was performed because the patient refused hysterectomy. Conclusions: Mullerian cervical adenosarcoma is a rare neoplasm with a recurrence rate that can reach up to $50 \%$ of cases, so close follow-up is necessary. A local excision can be considered in patients without poor prognosis factors and who wish to preserve their fertility.
\end{abstract}

KEY WORDS: Uterine sarcoma. Cervical Mullerian adenosarcoma. Cervix. Gynecological neoplasia.

\section{Resumen}

Antecedentes: El adenosarcoma mulleriano (AM) es una neoplasia ginecológica rara, de bajo potencial maligno, con crecimiento bifásico, constituida por un elemento epitelial benigno y otro mesenquimatoso maligno. Se presenta en todas las edades, pero predomina en mujeres posmenopáusicas. La localización cervical de los AM es poco frecuente; sin embargo, se asocia a una presentación en mujeres jóvenes. El diagnóstico se realiza mediante estudio anatomopatológico de la lesión e inmunohistoquímica. El pronóstico es generalmente bueno, aunque la tasa de recidiva es alta. Caso clínico: Presentamos el caso de una paciente de 27 años que acudió a consulta ginecológica con sangrado y flujo transvaginal. En la exploración ginecológica se identificó una lesión polipoide originada en el cérvix, la cual se extirpó por torsión y fue diagnosticada como AM cervical. Posteriormente se realizó conización cervical debido a que la paciente rechazó la histerectomía. Conclusión: El AM cervical es una neoplasia poco frecuente que tiene una tasa de recidiva que puede llegar hasta al $50 \%$ de los casos, por lo que es necesario un seguimiento estrecho. La escisión local puede ser considerada en pacientes sin factores de mal pronóstico y que deseen conservar su fertilidad.

PALABRAS CLAVE: Sarcoma uterino. Adenosarcoma mulleriano cervical. Cérvix. Neoplasia ginecológica.

\author{
Correspondence: \\ *Peter Grube-Pagola \\ Instituto de Investigaciones \\ Médico-Biológicas \\ Iturbide $\mathrm{s} / \mathrm{n}$, Zona Centro \\ C.P. 91700 , Veracruz, Ver., México \\ E-mail: grubejr78@gmail.com
}

Date of reception: 04-01-2018

Date of acceptance: 20-04-2018

DOI: 10.24875/CIRUE.M18000028
Cir Cir. 2019;87:172-176

Contents available at PubMed www.cirugiaycirujanos.com 


\section{Background}

Mullerian adenosarcoma (MA) was described by Clement and Scully in 1974 in the uterine body, which has been the most common presentation site, although it can occur in other locations such as the cervix, ovary, vagina, fallopian tube and intestinal serosa. It accounts for $5-7 \%$ of uterine sarcomas ${ }^{1-3}$, and MA of the cervix accounts for $2 \%$ of all $\mathrm{MAs}^{4}$. Cervical MA occurs more frequently in young women, with up to one third of them being reported in patients of between 10 and 15 years of age, with a marked difference with its counterpart in the uterine body, which usually occurs in postmenopausal women ${ }^{5}$. These are tumors of indeterminate etiology, with low malignant potential, characterized by a benign epithelial component and another malignant mesenchymal component, considered by some authors as an intermediate point along the path between adenofibroma and carcinosarcoma. Clinical presentation usually includes transvaginal bleeding or discharge, and sometimes a mass that protrudes up to the vagina can be identified $^{4,5}$. Definitive diagnosis is established by histopathology and immunohistochemistry testing. The most widely used treatment is hysterectomy with bilateral salpingo-oophorectomy; however, management of each case should be individualized. In general, the prognosis is good, although its biological behavior can sometimes be aggressive, with deep invasion of the myometrium and sarcomatous overgrowth being the main factors of poor prognosis. Metastases occur in $2 \%$ of cases, but the rate of local relapse is much higher, reaching up to $50 \%^{2,3}$.

The purpose of the presentation of this case is to emphasize on the importance of an adequate diagnosis and follow-up, given the high rate of recurrence, as well as treatment individualization, in accordance with all the principles of medical ethics.

\section{Clinical case}

This is the case of a 27-year-old woman who attended the gynecological outpatient clinic presenting with transvaginal bleeding and discharge. She had no hereditary, familial or personal history data of relevance. On obstetric-gynecological history, she referred menarche at 13 years, with regular menstrual cycles, moderate bleeding and 3 to 5-day-duration with no associated symptoms. She was nulliparous, had an active sexual life and did not use any contraception method.
Her current condition had started 3 months prior to attending the outpatient clinic, with foul-smelling transvaginal discharge of whitish to yellowish appearance, accompanied by intermittent, mild to moderate transvaginal bleeding, not related to menstruation or any traumatic factor; she had no other symptoms.

A colposcopy showed a lesion protruding through the external cervical foramen with areas of ulcerated appearance (Fig. 1). Biopsy and exfoliative cytology were obtained; the cytological report indicated chronic and acute inflammation with fibrin, while the biopsy report indicated a biphasic, ulcerated epithelial-mesenchymal neoplasm with stromal component atypia. Laboratory tests reported normal parameters (hemoglobin $11.55 \mathrm{~g} / \mathrm{dL}$, hematocrit $34.74 \%$, platelets

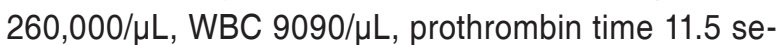
conds, partial thromboplastin time 29.7 seconds, glucose $70 \mathrm{mg} / \mathrm{dL}$, with the remaining blood chemistry values and lipid profile without alterations).

Subsequently, abdominal and transvaginal ultrasound showed a $73.7 \times 34.5 \times 51.2 \mathrm{~mm}$ uterus, myometrium with no apparent alterations, $8.8-\mathrm{mm}$ endometrium with thickening in the middle third consistent with submucosal myoma, cervix with deformed morphology at the expense of a solid invasive neoplastic process with mild vascularity (color Doppler), and ovaries with multiple cysts.

Exploration was carried out under anesthesia, with a $3 \mathrm{~cm}$ polypoid exophytic lesion, with pedicle originating from the endocervical canal, being found; the lesion was completely removed by torsion. Direct 7-cm hysterometry was performed with endometrial biopsy-curettage and, finally, bimanual exploration revealed uterus and adnexa without palpable masses, and free septa and parametria.

The polypoid lesion was grayish-brown in color, with a rubbery consistency, nodular surface, measuring $3.5 \times 2.5 \times 2.1 \mathrm{~cm}$. The cut surface of the mass was homogeneous, grayish-yellow in color and myxoid in appearance (Fig. 2). Histopathological examination showed a biphasic lesion with a solid growth pattern comprised of irregular cellular bundles with hypercellular and hypocellular areas interrupted by ducts of various sizes, from small to large, which gave a foliaceous-appearance pattern (Fig. 3). Immunohistochemistry reactions for estrogen receptors, progesterone receptors, smooth muscle actin and WT1 were carried out, which tested positive in the stromal component, and in addition showed positive-CD10 in the neoplastic cells adjacent to the epithelial component; the proliferation index via Ki67 was $5-8 \%$ (Fig. 4). The 


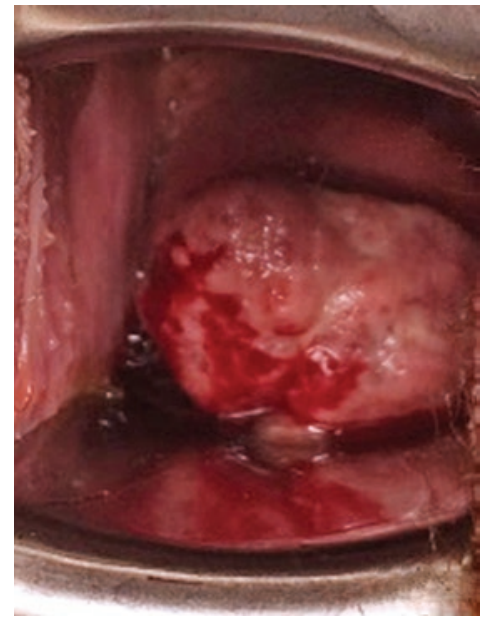

Figure 1. Macroscopic appearance of the neoplasm with ulcerated surface and hemorrhagic areas.
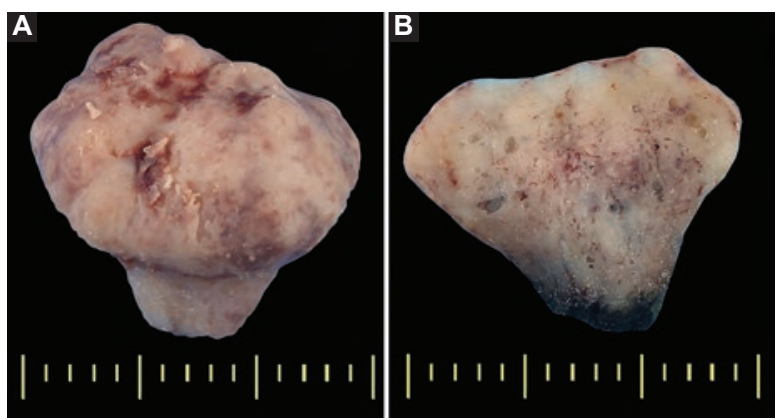

Figure 2. A: macroscopic appearance of the neoplasm: polypoid with pediculated base and the surface shows granulation tissue. B: cut surface of the mass is solid, with small cysts and accentuated vascularity.

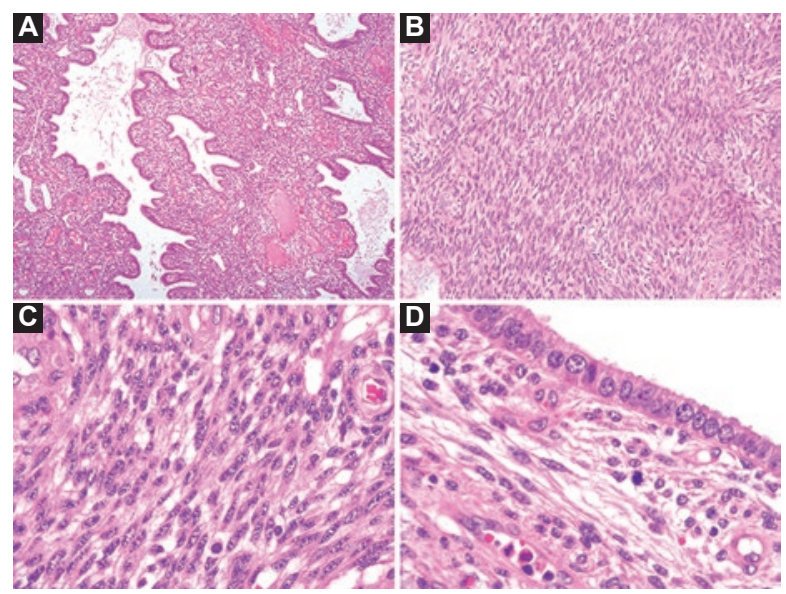

Figure 3. A: microscopic appearance with foliaceus pattern (hematoxylin \& eosin, 2x). B: in solid areas, the neoplasm grows forming short cell bundles (hematoxylin \& eosin, 10x). C: stromal cells are spindled, with cytoplasm with poorly defined borders and eosinophils; nuclei are elongated, with disperse granular chromatin (hematoxylin \& eosin, 40x). D: detail of the epithelial component, which is simple cubic without atypia; atypical mitosis is appreciated in the underlying stroma (hematoxylin \& eosin, 40x). diagnosis was Müllerian adenosarcoma. The endometrial biopsy showed simple hyperplasia changes without atypia.

The patient was proposed treatment with hysterectomy plus bilateral salpingo-oophorectomy or conservative with conization and close follow-up due to the risk of relapse, with the patient opting for the latter, due to her wish to get pregnant. Cervical conization was carried out uneventfully. The pathology analysis reported accentuated and focal acute chronic cervicitis with mature endocervical squamous cell metaplasia, without presence of neoplasm. The patient was discharged and a close follow-up plan was structured on an outpatient basis; currently, at 6 months and with a tomographic study, the patient is free of tumor activity.

\section{Discussion}

Uterine sarcomas are a group of neoplasms of mesenchymal origin, which account for $8 \%$ of malignant neoplasms of the uterus ${ }^{6}$. These neoplasms include MA, a tumor with low malignant potential that accounts for $5-8 \%$ of uterine sarcomas ${ }^{7}$, which was originally described by Clement and Scully in $1974^{1,2}$. It originates more often in the endometrium of the uterine body, but it can also develop in the ovary, the cervix ${ }^{1,5}$, the retroperitoneum and the intestine ${ }^{8}$. MA of the cervix accounts for $2-9 \%$ of all MAs ${ }^{7}$.

Cervical MA is a biphasic neoplasm, since it is composed of benign epithelium and malignant stroma ${ }^{4}$. Its etiology is unknown, although some cases have been associated with the use of oral contraceptives, tamoxi$\mathrm{fen}^{7}$, endogenous hyperestrogenism ${ }^{2}$, a history of pelvic radiation and a history of neoplasm ${ }^{1}$; in our case, the patient did not refer any relevant medical history data, although polycystic ovary was detected, which is a finding associated with endocrine alterations.

Cervical MA can occur in women of any age, but it is more common in young women, with a mean age of 27 years, as in our case, with $30 \%$ being reported in patients of between 10 and 15 years of age ${ }^{7}$.

The characteristic clinical presentation is with transvaginal bleeding ${ }^{1,4,9}$. In our patient, it was also associated with bacterial vaginosis, which is why initial treatment was based on antibiotic therapy. Other less common alterations associated with these cases are abdominal pain, urinary tract infections, uterine prolapse and even ascites ${ }^{1}$. Physical examination usually reveals a polypoid mass that protrudes through a dilated cervical duct, sometimes reaching up to the 


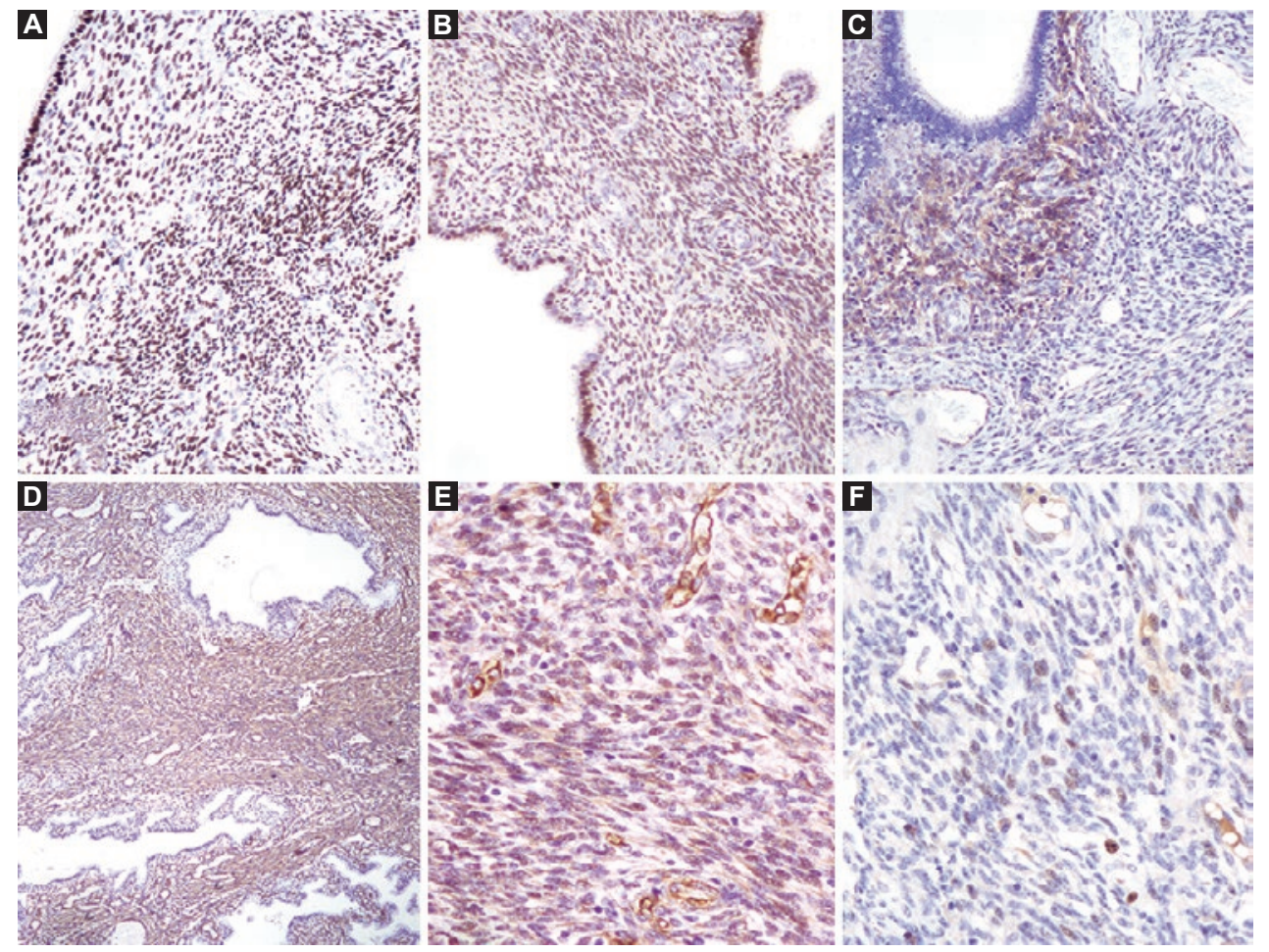

Figure 4. Positive immune reactions. A: estrogen receptors. B: progesterone receptors. C: CD10 in the cambium layer. D: smooth muscle anti-actin. E: Ki67 in 5-8\% of neoplastic cells.

vagina $^{1,2,5}$, which was identified in our case when a gynecological examination was performed under anesthesia, which allowed the excision of the tumor and an endometrial biopsy.

Laboratory tests were normal in our patient; there are no data reported on alterations associated with these cases. Imaging studies reveal well-delimited polypoid masses that can protrude through the endocervical canal or into the endometrial cavity. Areas of cystic appearance and septa can be observed together with a heterogeneous solid component ${ }^{6,10}$, with an enhancement similar to that of the endometrium after contrast medium administration ${ }^{2}$, in this case ultrasound (and color Doppler) being used, which revealed the lesion had some vascularity.

Macroscopically, the lesion size is variable $(5 \mathrm{~cm}$ on average), and a solitary, sessile or pedunculated, polypoid or papillary mass is typical, which projects towards its cavity (endocervical or myometrial), displaying a consistency that ranges from soft to firm (from gelatinous to fleshy or rubbery) ${ }^{1}$. The cut surface of the tumor can show cysts of varying size, areas of focal hemorrhage and necrosis, with a well-defined tumor margin; sometimes, multiple polyps are formed $^{1,3}$. In our case, it occurred as a $3.5-\mathrm{cm}$ lesion, predominantly solid, with a myxoid appearance and occasional cysts.
Microscopically, a biphasic neoplasm with a benign epithelial component and a malignant mesenchymal component is observed; at low magnification, this foliaceus pattern is reminiscent of a phyllodes tumor of the breast $^{2}$. The glandular epithelium is generally of the endometrioid type with cells of abundant eosinophilic cytoplasm, sometimes accompanied by mucosal and squamous differentiation ${ }^{2,3}$; it may exhibit nuclear atypia (large nuclei, pleomorphism, chromatin thickening, hyperchromasia, large nucleoli) and sometimes it forms lines between the stroma, conferring it a papillary or pseudovillous architecture'. The stroma is composed of rounded or fusiform cells, with varying degrees of atypia and hyperchromatic nuclei, which usually concentrate around glandular elements forming cuffs, also known as the cambium layer ${ }^{1,3}$; it can display projections in the lumen of the glandular component ${ }^{1}$. According to the World Health Organization criteria, the stromal component must exhibit a mitotic index $\geq 2$ mitotic figures per 10 high-power fields to differentiate it from adenofibroma. Most adenosarcomas contain a homogeneous mesenchymal component, but up to $25 \%$ may have heterologous elements (rhabdomyosarcoma, chondrosarcoma, liposarcoma, etc.) or a pattern of sarcomatous overgrowth $^{2,5,11}$, which did not occur in our case.

Immunohistochemistry reveals expression of cell differentiation markers (estrogen and progesterone, 
CD10 and WT1) in the stromal component. CD10 is particularly expressed in the cambium layer. Cell proliferation markers (Ki67) usually show low rates. However, in sarcomatous areas, cell proliferation is greater, as well as cell differentiation markers expression loss, with the immune profile being similar to that of undifferentiated uterine sarcoma. In some cases, aneuploid DNA is present ${ }^{2,3,12}$. Our case was confirmed by immunohistochemistry, showing a well-differentiated pattern.

Differential histological diagnoses include benign tumors, such as adenofibroma, atypical cervical polyp or adenomyoma of the cervix, as well as malignant neoplasms such as uterine adenosarcoma with extension to the cervix, carcinosarcoma and embryonic rhabdomyosarcoma ${ }^{5,9}$.

The main differential diagnosis is adenofibroma, but there is controversy in this aspect because the morphology, the immune profile and prognosis are similar, with differences only occurring when adenosarcomas have stromal overgrowth. Cases of adenofibroma with malignant behavior have also been reported, which is why this tumor has been proposed to be a well-differentiated adenosarcoma rather than a tumor that is different from adenosarcoma ${ }^{3,13}$.

There is no evidence regarding the most efficacious treatment, and following all that has been studied in MA of the uterine body, the most widely used treatment is hysterectomy with salpingo-oophorectomy; however, surgery with fertility preservation with negative tumor margins confirmation has been used as an alternative treatment ${ }^{1,4,5,7,11}$. Adjuvant therapies (chemotherapy or radiotherapy) have not shown any benefit in these cases $^{14}$. Since our patient refused hysterectomy owing to her wish to get pregnant in the future, local excision of the tumor and cervical conization to confirm negative margins was chosen. Anyway, the relapse rate is high, reaching $25 \%$ in patients treated with hysterectomy and up to $50 \%$ in those treated with local excision ${ }^{1,7}$; given that recurrence is common in the long term, close follow-up should be carried out ${ }^{1,5}$.

Sarcomatous overgrowth and myometrial invasion are the main factors of poor prognosis ${ }^{1,7,14}$, in addition to the presence of heterologous elements, high mitotic index, necrosis and extrauterine extension ${ }^{5,10}$. Lymph node involvement is $3-4 \%$ and 5 -year overall survival is $79 \%^{14}$. In our case, no factors of poor prognosis were found, but even so, the patient will be closely monitored due to the probability of relapse.

In conclusion, cervical MA is a neoplasm with low malignant potential and high relapse rate that exhibits an uncertain biological behavior, which is why longterm follow-up is necessary even after hysterectomy. Even so, it is feasible to consider a conservative treatment in those patients who wish to preserve fertility and who have no factors of poor prognosis, with close follow-up being established.

\section{References}

1. Clement PB, Scully RE. Mullerian adenosarcoma of the uterus: a clinicopathologic analysis of 100 cases with a review of the literature. Hum Pathol. 1990;21:363-81.

2. Friedlander ML, Covens A, Glasspool RM, Hilpert F, Kristensen G, Kwon S, et al. Gynecologic Cancer InterGroup (GCIG) consensus review for Mullerian adenosarcoma of the female genital tract. Int J Gynecol Cancer. 2014;24:S78-82.

3. McCluggage WG. Mullerian adenosarcoma of the female genital tract. Adv Anat Pathol. 2010;17:122-9.

4. Shinnick JK, Kumar N, Beffa L, Miller K, Friedman MA, Kalife E, et al. Management of low-grade cervical Müllerian adenosarcoma in a 14-yearold girl. J Pediatr Adolesc Gynecol. 2017;30:652-4.

5. Seagle BL, Falter KJ $2^{\text {nd }}$, Lee SJ, Frimer M, Samuelson R, Shahabi S. Mullerian adenosarcoma of the cervix: report of two large tumors with sarcomatous overgrowth or heterologous elements. Gynecol Oncol Case Rep. 2014;9:7-10.

6. Santos P, Cunha TM. Uterine sarcomas: clinical presentation and MRI features. Diagn Interv Radiol. 2015;21:4-9.

7. Kanayama S, Nakamura M, Oi H, Sugimoto S, Sasaki Y, Uchiyama T, et al. Case report of successful childbearing after conservative surgery for cervical Mullerian adenosarcoma. Case Rep Obstet Gynecol. 2017; 2017:4187416.

8. Daskalaki A, Xenaki S, Athanasakis E, Chrysos E, Chalkiadakis G. Advanced mesodermal (Müllerian) adenosarcoma of the ovary: metastases to the lungs, mouth, and brain. Case Rep Surg. 2015;2015:403431.

9. Podduturi V, Pinto KR. Mullerian adenosarcoma of the cervix with heterologous elements and sarcomatous overgrowth. Proc (Bayl Univ Med Cent). 2016;29:65-7.

10. Morales DA, Medina ML, Trujillo LM, Beltrán MI, Dulcey IC. Müllerian adenosarcoma of the uterine cervix with sarcomatous overgrowth: a case report of aggressive disease in a young patient. Int J Surg Case Rep. 2016;27:155-61.

11. Ramos P, Ruiz A, Carabias E, Piñero I, Garzón A, Álvarez I. Müllerian adenosarcoma of the cervix with heterologous elements: report of a case and review of the literature. Gynecol Oncol. 2002;84:161-6.

12. Soslow RA, Ali A, Oliva E. Mullerian adenosarcomas: an immunophenotypic analysis of 35 cases. Am J Surg Pathol. 2008;32:1013-21.

13. Gallardo A, Prat J. Mullerian adenosarcoma, a clinicopathologic and immunohistochemical study of 55 cases challenging the existence of adenofibroma. Am J Surg Pathol. 2009;33:278-88.

14. Seagle BL, Kanis M, Strohl AE, Shahabi S. Survival of women with Mullerian adenosarcoma: a National Cancer Data Base study. Gynecol Oncol. 2016;143:636-41. 